\title{
A landscape of open science policies research
}

Alejandra Manco

Laboratoire ELICO

Claude Bernard University Lyon 1

alejandra.manco-vega@univ-lyon1.fr

\begin{abstract}
Open science policies are a much-discussed issue. This literature review aims to examine the approach given to open science policy in these studies.

The approach given to open science in the selected works has different aspects: policy framing and its geopolitical aspects are described as an asymmetries replication and epistemic governance tool. The main geopolitical aspects of open science policies described in the literature are the relations between international, regional and national policies. There are also different components of open science covered in the literature: open data seems much discussed in the English speaking works while open access is the main component discussed in the Portuguese and Spanish speaking papers. Finally, the relation between open science policies and the general science policy is framed by highlighting the innovation and transparency that open science can bring to it.
\end{abstract}

\section{Keywords}

Open science, Open science policies, Europe, Latin America

\section{Introduction}

Open science implies the opening of all phases of scientific research. García Aristegui and Rendueles (2014) consider open science is often framed as apolitical but these authors believe that this is not the case; on the contrary, they agree that openness (and overall, the open movement) ultimately lies within the economic inequalities that already exist in the neoliberal framework. There are also divergent opinions about the globality of the value of open science. It is argued openness is usually progressive and differentiated (Fressoli and Arza, 2017) or that openness is not an intrinsic positive goal of science and needs to be promoted and rewarded at every step of the research process (Levin and Leonelli, 2017). 
Numerous reviews debate what open science is and what it encompasses. Several definitions have been proposed. For instance, Fecher and Friesike (2014) understand the term open science as an umbrella term that involves different understandings and viewpoints. Similarly, Abadal and Anglada (2020) argue that open science is not yet a welldelimited concept; its development depends on the advancements of each of its components. According to Vicente-Saez and Martinez-Fuentes (2018), open science is transparent and accessible knowledge shared and developed through collaborative networks. Furthermore, some reviews focus on particular subjects or specific countries publications on open science. Fell (2019) carried out a rapid evidence assessment on the economic advantages of open science and identifies two ways in which open science makes an economic impact: as efficiency, which refers to costs savings and productivity enhancement, and as enablement, the creation of new products, services, companies and collaborations. Another review from Ramírez-Montoya and García-Peñalvo (2018) concludes that most papers on open innovation focus on a business environment and academic environment. Nonetheless, there is still a literature review gap on open science policies. The main objective of this article is to review a variety of research works that explore open science policies or touch upon this subject and mainly explore the approach given to open science policy in these studies.

\section{Methodology}

To carry out this literature review we selected papers discussing open science policies as the main subject of study or articles that touch the subject tangentially. The content analysis was carried out using the software Nvivo12 for the coding and categorization process. The searches were made in Google Scholar, Semantic Scholar and Scopus using keywords such as open science and open science policy and its translations to the different languages used in this review: Spanish, Portuguese and French. The specific search strings and their results are available in Appendix A. The final list of documents and its source used in this review is available in Appendix $B$.

The research questions are listed below:

Which is the approach given to open science policy in the different studies?

Which components of open science are these papers covering?

Which are the main geopolitical aspects of open science policies?

How open science policies are framed in relation to science policy?

The selected articles have several interesting characteristics. The majority of the papers are written in English and come from countries from the global north (North America and 
Europe), then there is a major cluster of publications written in Portuguese from Brazil and the minority of papers are written in Spanish coming from Argentina and Spain and in French coming from France and Belgium. A regional approach of the papers can be seen in Figure 1:

\section{[ Regions and countries discussed in the open science policies articles ]}

0

17

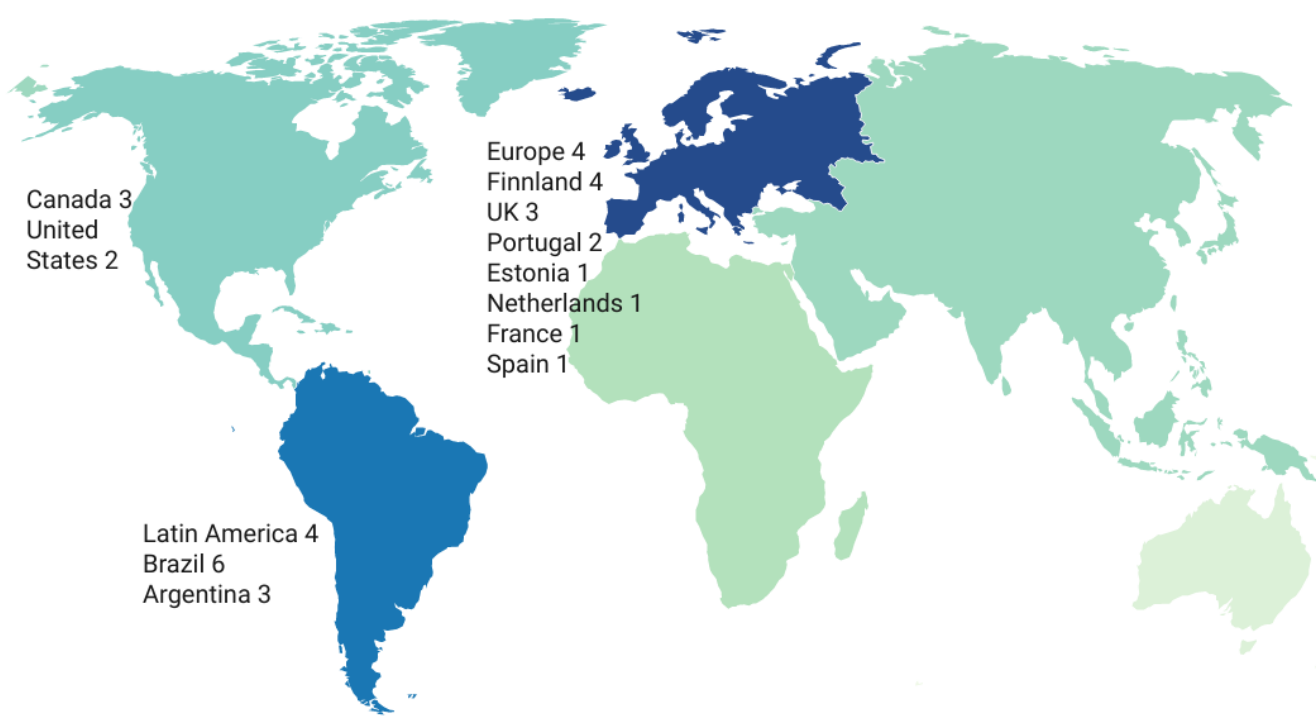

Map: Alejandra Manco $\cdot$ Created with Datawrapper

Figure 1: Regions and countries discussed in the reviewed open science policies articles

Building upon the papers abstract, we constructed a word cloud of the keywords from the articles. It is evident that open data and their related issues, such as data repository public data, research data etc. are the most prevalent issues after open science itself (Figure 2). 


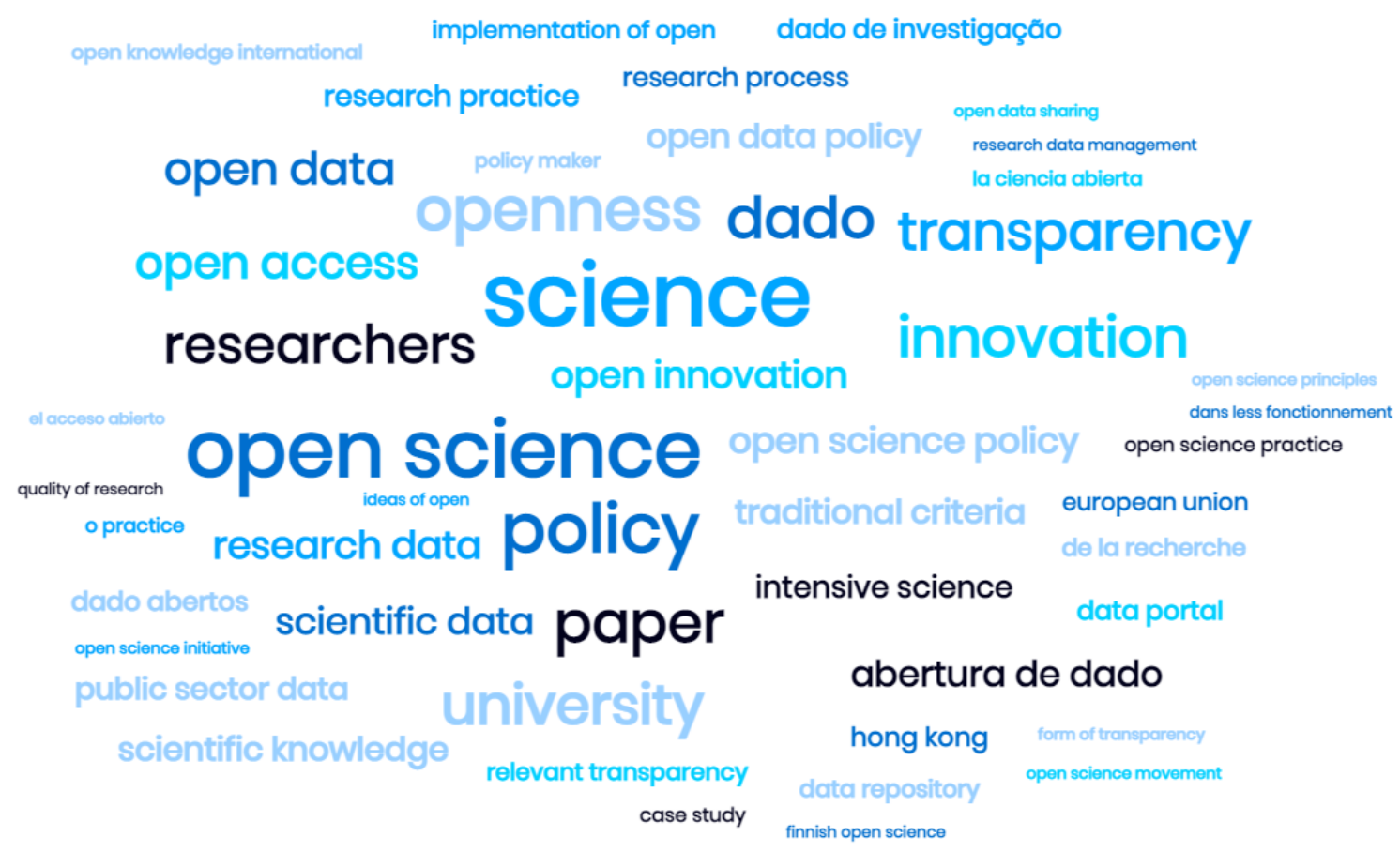

Figure 2: Word cloud generated from articles' abstracts

The selected papers came from different sources, such as journals, conferences and repositories (Figure 3). PLOS Biology is the source of four papers, LIBER Quaterly is the source of three papers while the conference ELPUB 2018 and the journals of Medicine, Health Care and Philosophy and Transinformação are the sources of two papers each. The rest of the sources have one selected paper. The complete list of sources used in this review is also available at Annex B. 


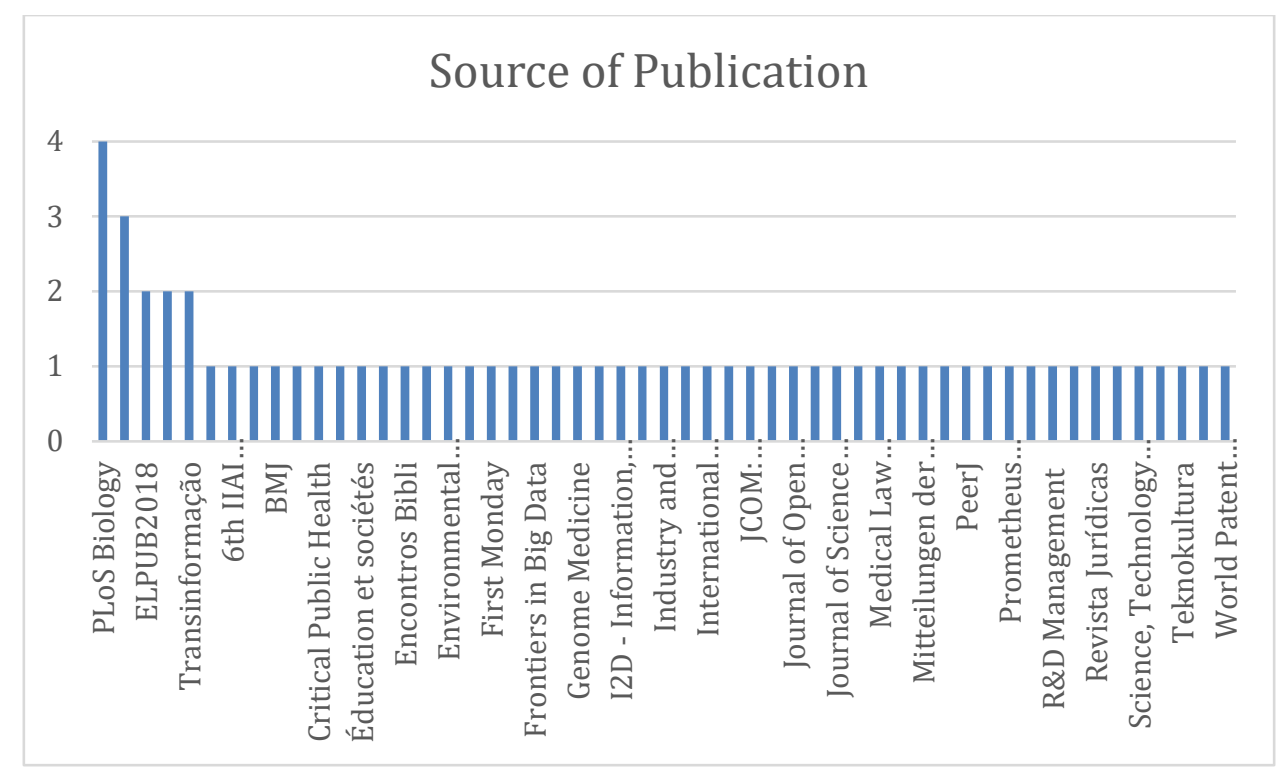

Figure 3: Source of Publication

The selected works were published between 2007 and 2021 (Figure 4). Two distinctive periods are observable in this interval: a first period of conceptualization of open science and their policies until before 2015 and a second period, which starts around 2016 and coincides with the surge and establishment of the open science movement. Moreover, starting from 2017 a sharp increase in studies on open science policy is observable, which correspond with the formulation and implementation of open science policy in various environments.

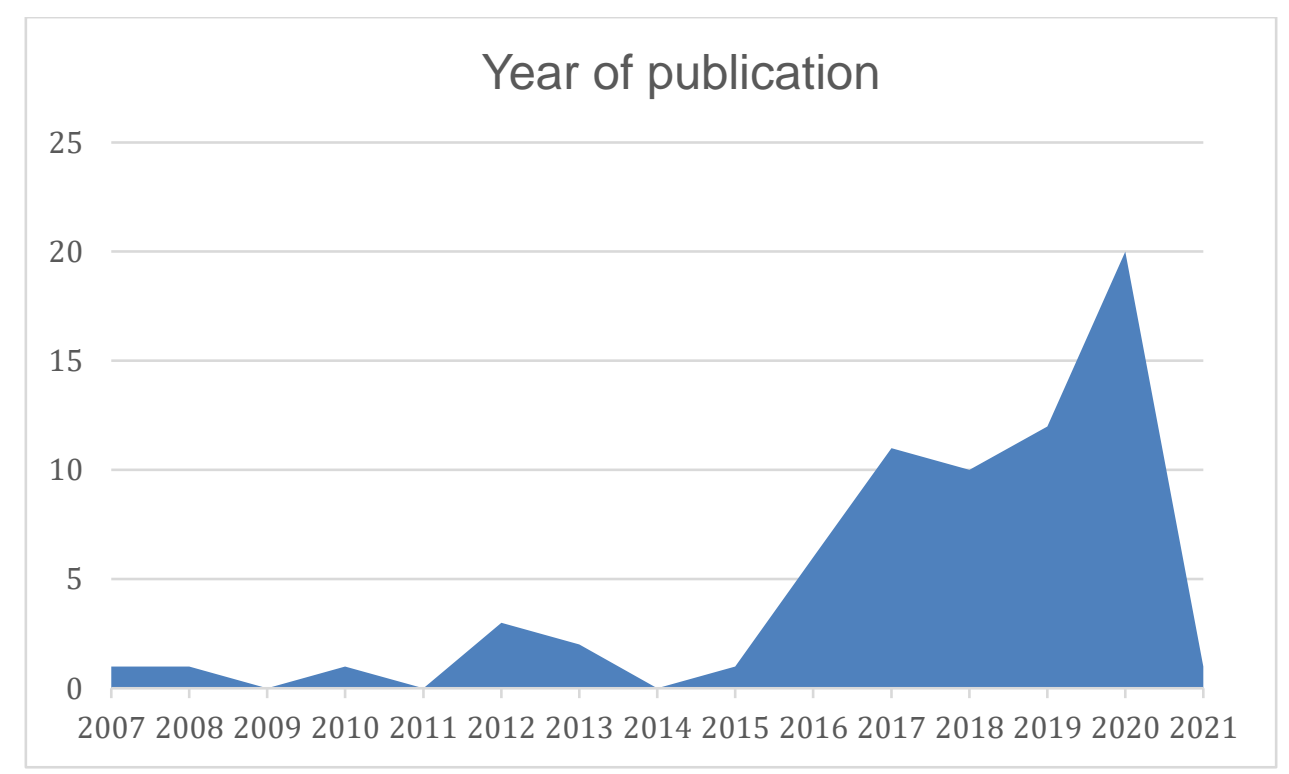

Figure 4: Year of publication 


\section{$\underline{\text { Results }}$}

This section revolves around how the concept of open science policy and its relations are approached in the different articles. It is organized in the following manner: it starts with the section about the approach to open science policy in the different studies, then the main components of open science covered in the papers are described, subsequently, the primary geopolitical elements of open science guidelines are discussed; finally, the remaining section is about how open science policies are framed concerning science policy.

\section{Approach to open science policy}

Back in 2010, Stodden (2010) argued that due to technological changes, the scale of rapid results has changed, so it is necessary to adopt policy countermeasures. According to this author (Stodden, 2010), these response measures should mainly include standards aimed at increasing transparency, as well as policy changes related to citizen scientists to increase their contributions; changes to data and code reuse. Advances in information and communication technology, as well as the growth of different kinds of digital platforms, are steadily changing open science policies and practices. (Vicente-Saez, Gustafsson and Van den Brande, 2020). Therefore, initiatives to develop and promote open science have been developed over the last decade (De Filippo and D'Onofrio, 2019). As for the perspective of open science, the trend towards openness will consolidate at a global level. Moreover, training and capacity building plans around the fields and practices of innovation and openness are very much needed to not be left behind (Fressoli and Arza, 2018).

Another important issue discussed in the literature is policy framing and its geopolitical aspects. In this regard, the geopolitics of open science is a complex issue as asymmetries in knowledge production and consumption are also replicated in the policies (Chartron, 2018). Moreover, Albornoz et al. (2018) propose that policies are tools of epistemic governance. These researchers examined at how open science is framed in policy: 1) open access and open data as key facilitators of open science; 2) open science as a means of enhancing scientific efficiency; 3 ) research infrastructures and data repositories as enablers of open science; 4) open science as a strategic advantage in a knowledge-based society and their competitiveness; 5) the private sector as a facilitator of scientific funding and expenditure; 6 ) the key beneficiaries of open science as researchers whose efficiency will be increased by open science; 7) open science as a catalyst of creativity and socioeconomic progress, or as

a response to global development challenges; and finally, 8) open science is also envisioned as a model for reducing dependency on today's subscription-based journal structure. 
An innovation frame is also observable. For instance, Vicente-Saez, Gustafsson and Van den Brande (2020) argue that open science policies and practices are expanding the university's scientific and innovative spirit. Furthermore, Caulfield, Harmon and Joly (2012) argue that integration and compatibility between innovation and open science policies. These authors argue that a fluid and streamlined approach to innovation is needed (Caulfield, Harmon and Joly 2012). Moreover, investment in open science is presented as a means to prevent the outflow of innovation and to gain the capabilities needed to maintain international competitiveness (Albornoz et al. 2018). Moreover, Ali-Khan, Harris and Gold (2017) argue that open science should not impose an additional burden on researchers, policies must make sharing easy, and structure should be built to enhance the competitiveness of researchers, research plans, and partnerships with patients and industry. Open science also has negative facets such as threads, conflicts and contradictions. A contradiction identified by Levin and Leonelli (2017) is the fact that open science policies are generally formulated in a general way with general principles (more often than not revolve around the economic value and data commodification), without taking into account particular differences in individuals, contexts or social processes. In addition, Elliott and Resnik (2019) find out that open science policies can create asymmetries between academic scientists who are forced to share their data and industry scientists who are not obligated to comply with such policies who are not required to follow such policies and, in some cases, open science policies can also suppress social accountability by aiding special interest interests in distorting scientific findings and misleading the public.

A conflict between commercialization and open science is also presented in the literature. Caulfield, Harmon and Joly (2012) argue that there is a resisting and conflicting coexistence between commercialization policies and open science policies. Moreover, there is a further contradiction in the formulation of research policies: they encourage openness while continuing to promote scientific production through intellectual property and patents. This issue may create difficult tensions (Fressoli and Arza, 2018).

\section{Actors, stakeholders and their institutional policies}

Among various institutions and scholars, openness is gaining traction (Smart et al., 2019). In the research environment, there is a variety of players. This section will highlight some of the stakeholders listed in the literature and their key role intertwined in the implementation of open science policies. Researchers are crucial actors in this type of environment. In this regard, Chataway, Parks and Smith (2017) argue that open science is consistent with many researchers' beliefs about the importance of knowledge exchange and collaboration. 
Therefore, universities should also develop policies and infrastructure to support open research programs (Smart et al., 2019). Moreover, Funamori (2017) concludes that academic institutions should adopt proposals for changing research strategies, faculty review, and research support structures, believing that these proposals will bring competitive advantages over peer institutions.

Policymakers are other key stakeholders in the research environment. These actors traditionally participate in scientific research by formulating science and innovation policies however with the advancement of open science, their role changes to active co-creators of scientific research through open and collaborative policymaking practices (Beck, et al. 2020). Funamori (2017) argue that policymakers should meet the needs of researchers and support the researcher's point of view of openness. Furthermore, aside from policymakers and managers but also coordinating bodies of higher education institutions such as rectors' councils and other institutions should also be aware of open science practices (De Filippo and D'onofrio, 2019). Similarly, research councils must also determine their requirements to fund new research streams and coordinate open methods in collaboration with the public, private, and third sectors (Smart et al., 2019). Furthermore, Hormia-Poutanen, Forsström (2016) argue that collaboration at different levels (national, disciplinary and role-related) are fundamental for the advancement of open science.

\section{Institutional policies}

This section discusses different implications for open science policies at an institutional level. Many institutions have started the development, adoption and implementation of open science policies mostly during the last ten years (Schmidt, et al., 2018; Kretser, et al., 2019). Furthermore, organizations must formulate policies, procedures and practices that address scientific integrity, provide personnel training, and continue to work hard to maintain awareness and advocate for these practices (Kretser, et al, 2019). In addition, it is argued that open science should be established as the standard operating procedure of the entire scientific enterprise (Kretser, et al, 2019).

Many academic institutions have research policies or research codes of practice, which clarify the principles, ethical basis and expectations of the behaviour of researchers in the institution. Seldom open science policies such as open access and open data are included in these research policies (Lyon, 2016).

Institutional open sciences policies have many characteristics on the way they ought to be constructed. For instance, Caulfield, Harmon and Joly (2012) assert that there must be a balance between funding and institutional policies, research guidelines, and project agreements as they must all recognize dualism and allow locals to choose courses that best 
meet the needs of the public. Similarly, rather than adopting a sole open science policy, departments at the institution should consider providing a disciplinary approach (Schmidt, et al., 2018).

About the discussion of top-down and bottom-up policies approach. Ali-Khan, Harris and Gold (2017) argue that institutional open science policies can only be successfully formulated in close cooperation with researchers, rather than in a top-down manner. Similarly, Margoni, Caso, Ducato, Guarda and Moscon (2018) argue that bottom-up interventions on open science policies seem more effective than the usual top-down approach to regulation.

\section{Components of open science covered in the literature}

Within the openness discussion, open access to publications has already reached a consensus, and open data is on the brink of doing so (Chataway, Parks and Smith, 2017). Furthermore, open data is one of the most critical facets of open science's progress (Burgelman et al., 2019). This is why, particularly in English-speaking countries, the topic of open data policies tends to be more evolved than the other components of open science. Open access, on the other hand, is a more established term in the realm of open science for Spanish and Portuguese journals than open data or altmetrics (De Filippo, Silva and Borges, 2019). The Latin American area is experiencing the same phenomenon.

For example, De Filippo and D'Onofrio (2019) argue that countries in the area should work hard to establish and enforce national policies that support various open science activities in a comprehensive and organized manner since although open access is a well-known problem, the other facets of open science are not. The next section will highlight the main aspects of open data mentioned in the literature.

\section{Open Data}

Open science has many aspects -as it is used as an umbrella term-, however, the aspect which is more studied concerning its policies is open data. This section will highlight the major issues within this concept.

It is argued that there are multiple benefits of open data. Open data contribute to the growth of new research that is unexpected (Maijala, 2016). Moreover, open data can contribute to open innovation. A change in focus from a sole open science data obligation to the identification of fundamental opportunities and the advancement of business models to capture them through open science initiatives is proposed by Roman, Liu \& Nyberg (2018). 
There is much discussion about open data policies at an institutional level. Joly, et al. (2012) analyse various data retention policies and publication moratoria. These authors observed that the rapid development of genomics research and biobanking has led to increasingly complex policies seeking to balance the interests of various stakeholders.

Gold (2016) explore a data policy initiative on open science at a hospital, they argue this initiative aims to promote the development of local innovation and the dissemination of university knowledge with the eventual goal of patent protection elimination.

At a university level, Helsinki University started a research data policy back in 2015 . This data policy states that the university will provide infrastructure, legal aid and training on related issues to research data management to scientists. In turn, researchers would have to draft and carry out a data management plan for their research projects. University libraries would also help with the policy implementation and research support (Hormia-Poutanen and Forsström, 2016).

Open data policies have also several implications. The application of the principles of unrestricted access to data and vastly extended provision of software services has resulted in the implementation of a fully Open Data policy on the creation of databases (Mancini, Lardo and De Angelis, 2020). Xafis and Labude (2019) debate about data repositories and their ethics in health research and how is the issue can be introduced in the policies to promote trustworthiness and transparency. Science Europe has collaborated with other research partners in recent years to facilitate a more harmonised approach to data sharing policies (Timmermann, 2019). Moreover, Rockhold (2019) study guidelines for clinical data sharing, and argues that open data policy implementation should be done in phases.

Data policies have also several actors. Kwon and Motohashi (2020) argue that policies on research data should institutionalize the legal protection of research data ownership and mandate research data disclosure. Gabrielsen (2020) argue that data policies should include digital curator communities which would give given more focus and jurisdiction, as well as frameworks to build and preserve trust. Curators should be included in the infrastructures for data-intensive research that are being developed.

\section{Open Access}

Institutional policies in the open access realm have been studied thoroughly. For instance, the institutional policies in the UK stipulate a specific funding mechanism for OA publications as these institutional policies are part of the legal system that encourages the publishing in gold OA (Margoni, Caso, Ducato, Guarda and Moscon, 2018). In the same regard, research funders are constantly requiring their grantees to disseminate using open access materials 
(Piwowar et al., 2018). Additionally, Biesenbender, Petersohn and Thiedig (2019) observed that reputation and institutional incentives may severely hinder the motivation of researchers to publish papers in OA journals or provide publications through OA. Moreover, at a regional level, according to De Filippo and D'Onofrio (2019) Latin American countries have been pioneer and active in reference on open access infrastructures and normative.

\section{Geopolitical Aspects of Open science Policies}

Open science public policy refers to national strategies and actions of organizations responsible for formulating and coordinating science and technology policies, funding agencies, and national research councils to promote their principles and practices (De Filippo and D'Onofrio, 2019). This section refers to international, regional and national policies of the European and Latin American regions.

\section{International policies}

Several international organizations are currently working on open science recommendations and policies. Moreover, the expansion of open science through the broadening of platforms where researchers share data, publications, experiments and equipment is driven by international and regional organizations (Babini and Rovelli, 2020). In addition, several international organizations and scientific institutions around the world have started to issue recommendations and policies for the implementation of open science practices. This fact may have serious implications since, as Albornoz, et al. (2018) argue the various mechanisms of knowledge transfer and consensus-building among international participants are not neutral; rather, they include negotiations that reflect unequal power relations in the global and local arenas.

This list includes multilateral organizations such as UNESCO, the Group of Seven, European Commission, the European Research Council and OECD; as well as international scientific societies, associations and industry publishing organizations, such as the International Science Council, the International Science Association and the STM Publishing International Association (Rentier, 2018; Fressoli and Arza, 2017; Albornoz et al., 2018). In addition, Oliveira \& Silva (2016) observe that concerning the proposal of open science policies there is a soft law that refers to rules that are not strictly binding, do not contain legal meaning, but can be used as principles to guide behaviour. In this regard, as maintained by Albornoz, et al. (2018) some international and European stakeholders have contributed to open science policies and projects in Latin America and Africa by funding and establishing partnerships. For instance, there is the significant influence of the European Commission, 
the Organization for Economic Cooperation and Development (OECD) and other government agencies have had a significant impact on policy guidelines in improving government transparency and public participation (De Filippo and D'Onofrio, 2019). At a practical implementation level, this trend is observable for instance at La Referencia. Araujo, Souza and Silva (2019) assert that it has established a series of interoperability guidelines. Participating countries must ensure its compliance, and recommends that the repositories that make up the network adopt these guidelines. The guidelines agreed on at the regional level are based on the OpenAIRE documentation adopted by the European Union.

\section{Regional and national policies: Europe}

Open Science policies have been developed and implemented in Europe for over ten years. The European Commission has been fundamental in the promotion of open science throughout the years openly and comprehensively, covering all aspects of the research cycle from scientific discovery and review to knowledge sharing, publication and promotion (Abadal and Anglada, 2021; Burgelman et al., 2019). Moreover, open science is one of the three main priority areas of the European Commission's science, research and innovation policy (Chataway, Parks and Smith, 2017).

In the realm of open science, originally called "Science 2.0 ", open access became the first area of European regulations (Vanholsbeeck, 2017). The Committee's communications and recommendations on access to scientific information put European open science in the context of the exoterisation research trend (Vanholsbeeck, 2017). European open science regulations are a way to overcome the intensified trend of ERA research. However, the trend of European open science and research management also has more management relations (Vanholsbeeck, 2017). In this regional realm, open science objectives are rather clear in all the reviewed policies, but the pending issues are located in the transition and the implementation of these policies into reality (Abadal and Anglada, 2021). Moreover, Chartron (2018) argues that open science harmonization in the European Union will be different to achieve since every country does not have the same priorities and neither the same funding for open science policies implementation.

National plans for open science from Finland, Slovenia, Netherlands and France were published within 2014 and 2018 (Abadal and Anglada, 2021). Finland's roadmap on open science dates back to 2014 (Maijala, 2016). Open science is defined as the unrestricted dissemination of research publications and data, based on the opportunities presented by digital transformation in France's national plan for open science (Schöpfel and Fabre, 2019). 
The national plan also commits to ensuring that the results of scientific research will not be delayed, and will not be hindered by all payment to personnel, researchers, companies and citizens (Schöpfel and Fabre, 2019). Moreover, this commitment mobilizes all higher education and research participants whose projects, initiatives and strategies create a dynamic and complex ecosystem that plays an important role in the evolution of publishers' strategic choices and their business models (Schöpfel and Fabre, 2019).

There are also practical applications provided by the literature. Biesenbender, Petersohn and Thiedig (2019) study three country-specific implementation cases in Italy, Netherlands and Germany. They identify that through institutionalized Current Research Information Systems (CRIS) infrastructure, open access repositories can be integrated into CRIS. Additionally, Bardi (2018) presents the OpenAIRE service, which fosters transparent evaluation of results and facilitates reproducibility of science for research communities by providing the open science infrastructure to do so. Finally, a further application of open science is in the creation of evidence-based policymaking. Open Science can make contributions to knowledge transfer from studies to policymaking (Olesk, Kaal and Toom, 2019).

\section{Regional and national policies: Latin America}

Thus far, there are currently several studies about open science and related issues in the Latin American region. De Filippo and D'Onofrio (2019) identify and analyse the main public policies of open science in Latin America, these authors examine the scientific achievements of the region in open science and analyse its main characteristics. They point out that in the majority of Latin American countries governmental science and technology policy entities are the ones promoting open infrastructure, open access, open data, open science policies. Moreover, the governmental offices of science, technology and innovation of countries such as Colombia, Mexico and Chile have issued their national policies on open science (Albornoz, et al., 2018).

It is argued that in this region the current evolvement to open science is built upon the open access movement as a basis (Bertin, Fortaleza, Da Silva and Okawachi, 2019; Babini and Rovelli, 2020).

Policies on open science in the region have some characteristics. For instance, in several statements in the region, knowledge is a concept introduced as a common good (Babini and Rovelli, 2020). Likewise, some researchers suspect that hegemonic open science can reproduce the colonial view of science, as if unregulated, it could leave to extract data from Latin America through the different capabilities to be exploited by developed countries to 
distinguish, process and extract knowledge (Clinio, 2019). By doing so, open science may contribute to the reproduction of existing inequalities in science.

Currently, there is not a formal open science policy in Brazil, however, there are many initiatives by public education and research institutions are motivated by the need to respond to the new demands of development agents - especially foreigner agents- and scientific journals (Clinio, 2019). Similarly, Costa (2020) argues about the need for those policies to establish some kind of guarantee to achieve international collaboration rather than dependence for researchers in Brazil. A Brazilian overview of regulatory frameworks that directly influence the practice of open science considering the sphere of government, institutions, funding agencies and institutions providing information products and services. The majority of the frameworks in this country are related to open data and open access (Rezende and Abadal, 2020).

Concerning the Argentinian case, Arza, Fressoli, and Sebastian (2017) emphasized open science practices. They argue that the country's policy should include new tools and incentive schemes to encourage collaboration at all stages of scientific knowledge production and more open and collaborative practices.

There are also some practical examples of open science infrastructure in the region. The Latin American repository network La Referencia has also produced their policy on open scientific infrastructure (Albornoz, et al., 2018). In addition, accordingly to the statement of research outputs as a public good, La Referencia Network promotes the national open access strategies of member countries using a platform with interoperability standards (Araujo, Souza and Silva, 2019).

\section{Open science framed in relation to science policy}

This section examines the relationship between open science and the overall science policies, focusing on the legal implications of open science policies, compliance challenges, and potential changes of the rewards' system in the research structure to achieve open science.

The literature on open science has highlighted several issues such as their relation to innovation and transparency and how it can contribute to science policy. It is argued that open science and their policies' implementation have many perceived benefits. For instance, Krishna (2020) argues that in crisis contexts open science policies can remove barriers to the free flow of research data and ideas, thereby accelerating the pace of research critical to disease prevention. Another advantage noted in the literature is the issue of transparency (and its principles), which has been included in the open science policy (Lyon, 2016). The 
motivations for addressing transparency as a concept have been articulated and the development of open science policy, which embraces transparency principles, has been described. Open science strategies pursuing socially relevant transparency is also mentioned as a basis for effective science translation, science communication and public engagement with it (Elliott and Resnik, 2019).

Open science policies implementation has some implications that may collide with the current legal and intellectual property systems. Historically, the practice of secrecy in science is encouraged prior to patent and is maintained after patenting, making research communication difficult. Moreover, Gabrielsen (2020) argue that in the current science policy, the importance of trust has decreased, and there is a tendency towards openness and transparency. The lack of consensus on the establishment of grace periods (as an exception, allowing inventions to be disclosed before patent applications) has created legal uncertainty (Wong, Ramos-Toledano, Rojas-Mora, 2018). Additionally, it is argued by Kelty (2012) openness is opposed by the fact that certain fields such as biotechnology and pharmaceuticals are dominated by patents in order to enhance a competitive market. Furthermore, Kelty (2012) argues that a strong intellectual property system requires that all concepts, technologies, claims, or results that are generated should be owned separately, rather than collectively owned concepts and technologies that lead to a combination of collaboration and competition. Moreover, open science is located between two ethicalcultural-legal spectra, according to Oliveira and Silva (2016): 1) the transition from a proprietary economic paradigm that reinforces private intellectual property rights to the paradigm of sharing, and 2) the emphasis of the new scientific paradigm based on research data and the culture of commons.

\section{Open science policies implementation}

Despite the multiple perceived benefits of open science such as achieving a more productive, democratic, and egalitarian research practices, there are still issues in policies implementation (Levin et al., 2016). Previous research has established that there is a gap in the implementation and adoption of open science policies (Kretser, et al., 2019; Armani, et al., 2020). Moreover, Schmidt, et al. (2018) argue there is a challenge on communication and implementation of institutional policies on open science. In addition, in the open access field the same phenomenon occurs: Saraite Sariene, Caba Pérez and López Hernández (2020) in their study about open access policies in higher education conclude that despite different policies, so far the implementation of open access policies is still at a moderate level. 
Strategies in different dimensions such as new metrics for science evaluation, development of infrastructures, legal frameworks are essential for an open science policy implementation (Santos, 2017).

A scientific communication ecosystem as an enabler of transparency and reproducibility is a main infrastructure of open science. This open science ecosystem implementation will need to provide tools and policies related to sharing, interlinking and reusability of research artefacts (Bardi, 2018). Similarly, Rockhold et al. (2019) study guidelines for clinical data sharing, they argue that open data policy implementation should be done in phases.

There are several recognized reasons for this gap. For instance, Aguinis, Banks, Rogelberg, Cascio (2020) argue there is a gap between practice and theory in open science due to a disagreement between different science stakeholders. Similarly, Levin et al. (2016) state that the implementation of open science requires a number of shifting prospects for multiple stakeholders. Furthermore, Armani et al. (2020) identify three main reasons for this gap: the difficulty to reach a critical mass, the perceived cost of change and several disciplinary differences. In the same way, Levin et al. (2016) argue that one of the issues is that policies seem to refer to all research stages in different fields without any differentiation. Moreover, Saraite Sariene, Caba Pérez and López Hernández (2020) assert that the reputation of the university seems to influence the university's better adoption of open access policies.

Capacity building is needed argue Fressoli and Arza (2018) as implementing open scientific practice involves learning new skills that are not always available for researchers. Finally, Vicente-Saez, Gustafsson and Van den Brande (2020) argue that there is already a shift towards openness of the research process. This conveyance is focusing more on the procedures such as open sharing practices, open protocols, open data sharing or open repositories, and open invitation practices while the current policies at the national, regional, and international level tend to focus on the openness of research outputs such as open access or open data. Therefore, there is currently an imbalance between open scientific practices and open science policies.

\section{Changes the rewards' system in the research environment to achieve open science}

Several studies suggest that there is a lack of incentives for open science in the current research assessment. Despite the fact that the vast majority of scientists support open science, few actually practice it (Heise and Pearce, 2020). For instance, academic incentive 
structures should be adjusted and restructured to align with open science policies and allow for some level of response (Armeni et al., 2020).

The current incentive mechanism of contemporary academia does not promote data sharing before publication (Kamoun, Talbot and Islam, 2019). Moreover, a recognition system different to the "publish or perish" approach is needed to improve the adoption of open science (Howe, Howe, Kaleita and Raman, 2020). In this regard, Robinson Garcia, Costas and van Leeuwen (2020) assert that science policies should introduce metrics of openness. In the policy debate on the impact of competitiveness, the issue about the university's agenda and commercialization policy should be based on an understanding of the specific institutional context under consideration (Walsh and Huang, 2014). Furthermore, the commercialization of research has become an indispensable portion of academic policy (Krishna, 2020).

Previous research has established that open science feasibility is based on incentives (Mukherjee and Stern, 2009; Kraker, Leony, Reinhardt and Beham, 2012). Current local incentive programs do not promote these open science practices but prevent them by incurring opportunity costs of using the time to conduct activities that are not valued by the evaluation program (Fressoli and Arza, 2018). This is the reason why various authors discuss the need to implement a change in the reward's system for open science mainstreaming. For example, Funamori (2017) argues and proposes an integral research evaluation reform. Specific to the open data realm, Levin et al. (2016) recommend that due to the current conflict between transparency and commercialization, a reform of promotion and tenure policies is required to achieve open science and, in particular, open data principles. Similarly, at a university level, it is argued that these institutions should also develop infrastructure and training to support, measure, and reward work that fulfils open science principles (Howe, Howe, Kaleita and Raman, 2020).

There are also concerns over the rewards' system in these current regional policies in the literature. For instance, Schöpfel and Fabre (2019) state that the open science policies of the European Union, major funding agencies and major research organizations do not seem to raise questions about the current scientific journal model. On the contrary, they strengthen the function of journals to disseminate research results. Furthermore, Burgelman, et al. (2019) argue that necessary changes to the reward and incentive system for researchers are still missing various European open science policies. In the same regard, according to Abadal and Anglada (2021), the evaluation model and the need for researchers' habit change seem to be the biggest pitfall for open science.

Research proposes models in the research evaluation. For instance, Chataway, Parks and Smith (2017) propose creating their monitoring and evaluation approach for open science. 
Similarly, Kittrie, et al. (2017) discuss a prize awarded as a funding model change to incentivize open science. This prize was useful to enhance international collaborations and open digital content. Lastly, the most recent research has focused on open science and its role in research assessment. Moher et al. (2020) outline new research assessment criteria to enhance research integrity and advance open science practices for research institutions and their funding policies. Likewise, Rice, Raffoul, loannidis and Moher (2020) research different research assessment practices. Finally, any type of assessment revision necessitates international coordination and synchronization. Rentier (2018) makes the case that if this is not done, early adopter researchers will be at a disadvantage.

\section{Discussion}

Open science is promptly becoming a mainstream issue, with a wide variety of direct and indirect players and stakeholders in various nations, territories, and at the international level discussing it. In this discussion, two distinct phases can be discerned: a first phase of conceptualization of open science and its policies until before 2015, and a second period, beginning in 2017 , with a sharp rise in research on open science policy, which correlates to the formulation and enforcement of open science policy in different settings. This implementation is likely to continue over the upcoming years. This literature review has brought forward this discussion by pointing out the different approaches to this issue. The approach given to open science in the studies has different frames. On the one side, policy framing and its geopolitical aspects are defined as a mechanism for reproduction of asymmetries and epistemic governance. On the other hand, open science is framed as an innovation catalyst, and as a result, its policies encourage its advancement. Finally, there are also some disadvantages of open science policies: a generalization argument of open science may lead to disparities between researchers and organisations who must follow open science policies and those who do not. There are indeed conflicts between commercialization and open science policies.

The policy literature covers a variety of open science components; however, there are noticeable variations between regions and languages. The subject of open data policy is more developed in English-language works than the other components of open science. Open access, on the other hand, seems to be a well-established subject in Spanishspeaking research. Overall, this corpus seems to rely on these two issues: open data and open access; as a result, open science policy work seems to focus more on open outputs than on other aspects of the scientific process. Certainly, the fact that open science policies research is mostly written in a particular language and from a particular given nation and 
regions brings into doubt the concept's purported universality. Specially, how policies based on this concept could potentially replicate - unintentionally or intentionally - current inequalities in terms of the difficulties of conducting science in different countries and regions and given the political economy of the different stakeholders in the current research infrastructure.

The major geopolitical dimensions of open science policies described in the literature are first and foremost its various actors and stakeholders, such as academics, universities and research agencies, policymakers, and research councils, and how each of these actors and stakeholders plays a unique role in institutional, state, regional, and international open science policies.

Open science recommendations, mandates, and policies are now being developed by a number of major international organizations. This fact may have significant ramifications as policymaking may replicate current inequalities on a global scale. At a regional level, for many years, the European Commission has been proposing policy recommendations at the regional level. Open science policies have been advocated, debated, and written the national level in this area, but their adoption is still lacking. The Latin American area has a number of policy proposals as well, but this is not made through international organizations. In particular, in contrast to the European regional situation, the Latin American literature focuses more on case studies at the institutional or national level rather than on large regional organizations supporting regional open science policies. Another significant point to note in this area is that open access is the foundation for open science policy, since this topic has been extensively debated, studied, and pursued in the past in this region.

The relationship between open science and science policy is defined by the innovation and transparency that open science will bring to the table. However, the relationship between open science and the intellectual property law is still discussed. Finally, there is currently a gap between open science policies and their implementation. Several studies contend that changing the scientific environment's incentive mechanism is critical to achieving open science deployment.

\section{Conclusions}

Unquestionably, the discussion of open science policies and their possible fulfilment between their different actors and stakeholders will continue over the next years. This review contributes to this discussion by highlighting what it has been said about this subject in four different languages. By doing so, we aimed to provide a more inclusive and balanced 
landscape of this subject; however, the language choice is probably also a study limitation as well as there is much discussed about open science policies in other languages.

Finally, the main limitation of this literature review is the fact that the selected papers for this paper were mainly located in the fields of science and technology. Further research could focus on the literature corresponding to open science policies selecting specifically works on the fields of humanities and social sciences, which may lead to quite different results.

\section{References}

Abadal, E. \& Anglada, L. (2020) Open science: Evolution of the name and the concept. Anales de Documentación 23. doi:10.6018/analesdoc.378171

Abadal, E. \& Anglada, L. (2021) Políticas de ciencia abierta en Europa. In Borges, M.M. \& Sanz Casado, E. (Eds.), Sob a lente da Ciência Aberta: Olhares de Portugal, Espanha e Brasil (pp. 45-66). Universidade de Coimbra. doi: https://doi.org/10.14195/978-989-26-2022$\underline{0}$

Aguinis, H., Banks, G.C., Rogelberg, S. G. \& Cascio, W. F. (2020) Actionable recommendations for narrowing the science-practice gap in open science. Organizational Behaviour and Human Decision Processes 158. doi:

https://doi.org/10.1016/j.obhdp.2020.02.007

Albornoz, D., et al. (2018) Framing Power: Tracing Key Discourses in Open Science Policies. ELPUB 2018, Toronto, Canada. doi: 10.4000/proceedings.elpub.2018.23. hal01816725

Ali-Khan, SE., et al. (2017) Point of view: Motivating participation in open science by examining researcher incentives. eLife. doi:https://doi.org/10.7554/eLife.29319.001 Araujo I. A. de, Souza L. G. S. \& Silva C. M. A. da (2020) LA Referencia: uma contribuição para o ecossistema de ciência aberta na América Latina. Ciência da Informação, 48(3). http://revista.ibict.br/ciinf/article/view/4853

Armeni, K., et al. (2020) Towards wide-scale adoption of open science practices: The role of open science communities, MetaArXiv. doi:https://doi.org/10.31222/osf.io/7gct9

Arza, V., Fressoli, M. \& Sebastian, S. (2017) Towards opens science in Argentina: from experience to public policies. First Monday, 22(7). doi:https://doi.org/10.5210/fm.v22i7.7876 Babini, D. \& Rovelli, L. eds. (2020) Tendencias recientes en las políticas científicas de ciencia abierta y acceso abierto en Iberoamérica. Buenos Aires: CLACSO, Fundación Carolina. URL: https://www.clacso.org.ar/librerialatinoamericana/libro detalle.php?id libro=2279\&pageNum rs libros=0\&totalRows rs libro $\underline{S=1461}$ 
Bardi, A. (2018). Open Science as-a-Service for Research Communities and Content Providers. International Conference on the Economics of Grids, Clouds, Systems, and Services. doi: https://doi.org/10.1007/978-3-030-13342-9 1

Beck, S., et al. (2020) The Open Innovation in Science research field: a collaborative conceptualisation approach, Industry and Innovation. Industry and Innovation. doi: 10.1080/13662716.2020.1792274

Bertin, P.R.B, Fortaleza, J.M., Da Silva, A.C. \& Okawachi, M. F. (2019) A parceria para Governo Aberto como plataforma para o avanço da Ciência Aberta no Brasil.

Transinformação 31. doi: https://doi.org/10.1590/2318-0889201931e190020

Biesenbender, S., Petersohn, S. \& Thiedig, C. (2019) Using Current Research Information Systems (CRIS) to showcase national and institutional research (potential): research information systems in the context of Open Science. Procedia Computer Science 146. doi:https://doi.org/10.1016/j.procs.2019.01.089

Burgelman J-C., Pascu C., Szkuta K., Von Schomberg R., Karalopoulos A., Repanas K. \& Schouppe M. (2019) Open Science, Open Data, and Open Scholarship: European Policies to Make Science Fit for the Twenty-First Century. Frontiers Big Data 2:43. doi: 10.3389/fdata.2019.00043

Caulfield, T., Harmon, S.H.E. \& Joly, Y. (2012) Open science versus commercialization: A modern research conflict? Genome Medicine 4. doi:10.1186/gm316

Chartron, G. (2018). L'Open science au prisme de la Commission européenne. Éducation et sociétés, 41(1), 177-193. doi:https://doi.org/10.3917/es.041.0177

Chataway, J., Parks, S. \& Smith, E. (2017) How will open science impact on universityindustry collaboration? Foresight and STI Governance 11, 44-53. doi:10.17323/25002597.2017.2.44.53

Clinio, A. (2019) Ciência Aberta na América Latina: duas perspectivas em disputa. Transinformação, 31. doi: https://doi.org/10.1590/238180889201931e190028 Costa, M. (2020) Políticas de Ciência Aberta e a abertura dos dados de pesquisa. In: Tópicos sobre dados abertos para editores científicos Organizadores: Políticas de Ciência Aberta e a abertura dos dados de pesquisa. São Paulo: Associação Brasileira de Editores Científicos. https://ridi.ibict.br/handle/123456789/1072

Da Silva, P. F. P. (2017) As políticas de Open Data em Portugal: análise da sua implementação e impacto. Coimbra University. Master Degree Thesis in Information Science. URL: https://estudogeral.uc.pt/handle/10316/47025

De Filippo, D., Silva, P. \& Borges, M.M. (2019) Caracterización de las publicaciones de España y Portugal sobre Open Science y análisis de su presencia en las redes sociales. Revista Española de Documentación Científica 42. doi:10.3989/redc.2019.2.1580 
De Filippo, D. \& D'Onofrio, MG. (2019) Alcances y limitaciones de la ciencia abierta en Latinoamérica: análisis de las políticas públicas y publicaciones científicas de la región. Hipertext.net 19. doi:10.31009/hipertext.net.2019.i19.03.

Elliott, K.C. \& Resnik, D.B. (2019) Making open science work for science and society. Environmental Health Perspectives. doi:10.1289/EHP4808

Fecher, B. \& Friesike, S. (2014) Open Science: One Term, Five Schools of Thought. In: Bartling S., Friesike S. (eds) Opening Science. Springer. doi: https://doi.org/10.1007/978-3319-00026-8 2

Fell, M.J. (2019) The economic impacts of open science: A rapid evidence assessment. Publications. doi:10.3390/PUBLICATIONS7030046

Fressoli, M. \& Arza, V. (2017) Negociando la apertura en ciencia abierta. Un análisis de casos ejemplares en Argentina. Revista Iberoamericana CTS, 12(36), 139-162. URL:

http://www.revistacts.net/contenido/numero-36/negociando-la-apertura-en-ciencia-abiertaun-analisis-de-casos-ejemplares-en-argentina/

Fressoli, M. \& Arza, V. (2018) Los desafíos que enfrentan las prácticas de ciencia abierta. Teknokultura. Revista de Cultura Digital y Movimientos Sociales, 15(2), 429-448. doi: 10.5209/TEKN.60616.

Funamori, M. (2017) Open Science and the Academy: A Theoretical Discussion. 6th IIAI International Congress on Advanced Applied Informatics (IIAI-AAI), Hamamatsu. doi: 10.1109/IIAI-AAI.2017.19.

Gabrielsen, A.M. (2020) Openness and trust in data-intensive science: the case of biocuration. Medicine, Health Care and Philosophy 23, 497-504. doi:

https://doi.org/10.1007/s11019-020-09960-5

Garcia Aristegui, D. \& Rendueles, C. (2014) Abierto, libre... y público. Los desafíos políticos de la ciencia abierta. Argumentos de Razón Técnica, 17, 45-64.

URL:http://hdl.handle.net/11441/48209

Heise, C., \& Pearce, J. M. (2020). From Open Access to Open Science: The Path From Scientific Reality to Open Scientific Communication. SAGE

Open. https://doi.org/10.1177/2158244020915900

Hormia-Poutanen, K. \& Forsström, P.L. (2016) Collaboration at International, National and Institutional Level - Vital in Fostering Open Science. LIBER Quarterly, 26(1), pp.3-12. DOI: http://doi.org/10.18352/lq.10157

Howe A, Howe M, Kaleita AL \& Raman DR. (2017) Imagining tomorrow's university in an era of open science. F1000Research. 6:405. doi:

https://doi.org/10.12688/f1000research.11232.2 
Joly, Y. et al. (2012) Open science and community norms: Data retention and publication moratoria policies in genomics projects. Medical Law International, 12(2), 92-120. doi: $10.1177 / 0968533212458431$.

Kamoun S, Talbot NJ \& Islam MT. (2019) Plant health emergencies demand open science: Tackling a cereal killer on the run. PLoS Biology 17(6): e3000302.

https://doi.org/10.1371/journal.pbio.3000302

Kelty, C.M. (2012) This is not an article: Model organism newsletters and the question of "open science". BioSocieties 7, 140-168. doi:10.1057/biosoc.2012.8

Kittrie, E. et al. (2017) Developing international open science collaborations: Funder reflections on the Open Science Prize. PLoS Biology 15(8): e2002617.

https://doi.org/10.1371/journal.pbio.2002617

Kraker, P., Leony, D., Renhardt, W. \& Beham, G. (2012) The case for an open science in technology enhanced learning. International Journal of Technology Enhanced Learning 3(6). doi: https://doi.org/10.1504/IJTEL.2011.045454

Kretser, et al. (2019) Scientific Integrity Principles and Best Practices: Recommendations from a Scientific Integrity Consortium. Science and Engineering Ethics 25, 327-355. doi:10.1007/s11948-019-00094-3

Krishna, V.V. (2020) Open science and its enemies: Challenges for a sustainable sciencesociety social contract. Journal of Open Innovation: Technology, Market, and Complexity 6. doi:10.3390/JOITMC6030061

Kwon, S. \& Motohashi, K. (2020) Incentive or Disincentive for Disclosure of Research Data? A Large-Scale Empirical Analysis and Implications for Open Science Policy. Tokio: Research Institute of Economy, Trade and Industry. RIETI Discussion Paper Series.

https://www.rieti.go.jp/en/publications/summary/20060005.html

Levin, N., et al. (2016) How Do Scientists Define Openness? Exploring the Relationship Between Open Science Policies and Research Practice. Bulletin of Science; Technology \& Society, Vol. 36(2) 128-141.

Levin, N. \& Leonelli, S. (2017) How Does One "Open" Science? Questions of Value in Biological Research. Science, Technology, \& Human Values, 42(2), 280-305. doi: $10.1177 / 0162243916672071$.

Lyon, L. (2016) Transparency: The emerging third dimension of open science and open data. LIBER Quarterly 25, 153-171. doi:10.18352/lq.10113

Maijala, R. (2016) Joining networks in the world of open science. LIBER Quarterly 26, 104124. doi:10.18352/lq.10179

Mancini, D., Lardo, A. \& De Angelis, M. (2020) Efforts Towards Openness and Transparency of Data: A Focus on Open Science Platforms. In: Lazazzara A., Ricciardi F., Za S. (eds) 
Exploring Digital Ecosystems. Lecture Notes in Information Systems and Organisation, vol 33. Springer, Cham. https://doi.org/10.1007/978-3-030-23665-6 6

Margoni, T., Caso, R., Ducato, R., Guarda, P. \& Moscon, V. (2018) Open Access, Open Science, Open Society. SSRN Electronic Journal. doi:10.2139/ssrn.2751741

Moher, D., et al. (2020). The Hong Kong principles for assessing researchers: Fostering research integrity. PLoS Biology, 18(7). https://doi.org/10.1371/journal.pbio.3000737 Mukherjee, A. \& Stern, S. (2009) Disclosure or secrecy? The dynamics of Open Science. International Journal of Industrial Organization 27, 449-462.

doi:10.1016/j.jindorg.2008.11.005

Olesk, A., Kaal, E. \& Toom, K. (2019) The possibilities of Open Science for knowledge transfer in the science-policy interface. JCOM 18 (03), A03. doi:

https://doi.org/10.22323/2.18030203.

Oliveira, A. \& Silva, E. (2016) Ciência aberta: dimensões para um novo fazer científico. Informação \& Informação 21(2). doi:10.5433/1981-8920.2016v21n2p5

Piwowar, $\mathrm{H}$, et al. (2018). The state of OA: a large-scale analysis of the prevalence and impact of Open Access articles. PeerJ 6:e4375 https://doi.org/10.7717/peeri.4375 Ramírez-Montoya, M. \& García-Peñalvo, F. 2018. Co-creación e innovación abierta: Revisión sistemática de literatura. Comunicar, 54, 09-18. doi:https://doi.org/10.3916/C542018-01

Rezende, LVR. \& Abadal, E. 2020. Estado da arte dos marcos regulatórios brasileiros rumo à Ciência Aberta. Encontros Biblio, 25. doi: https://doi.org/10.5007/1518-2924.2020.e71370 Rentier, B. (2018) Science ouverte, le défi de la transparence. Brussels: Académie Royale de Belgique. URL: https://orbi.uliege.be/handle/2268/230014

Rice, D. B., Raffoul, H., loannidis, J. P. A., \& Moher, D. (2020). Academic criteria for promotion and tenure in biomedical sciences faculties: cross sectional analysis of international sample of universities. BMJ (Clinical Research Ed.), 369, m2081. https://doi.org/10.1136/bmj.m2081

Robinson-Garcia N, Costas R \& van Leeuwen TN. 2020. Open Access uptake by universities worldwide. PeerJ. doi:https://doi.org/10.7717/peerj.9410

Rockhold, F., Bromley, C., Wagner, E. K., \& Buyse, M. (2019). Open science: The open clinical trials data journey. Clinical Trials, 16(5), 539-546.

https://doi.org/10.1177/1740774519865512

Roman, M., Liu, J. \& Nyberg, T. (2018) Advancing the open science movement through sustainable business model development. Industry and Higher Education, 32(4), pp. 226234. doi: $\underline{10.1177 / 0950422218777913}$. 
Santos, P. X., coord. (2017) Livro Verde - Ciência aberta e dados abertos: mapeamento e análise de políticas, infraestruturas e estratégias em perspectiva nacional e internacional. Rio de Janeiro: Fiocruz. https://www.arca.fiocruz.br/handle/icict/24117 Saraite Sariene, L., Caba Pérez, C. \& López Hernández, AM. (2020) Expanding the actions of Open Government in higher education sector: From web transparency to Open Science. PLoS ONE 15(9): e0238801. doi: https://doi.org/10.1371/journal.pone.0238801

Schmidt B, et al. (2018) Open Science Support as a Portfolio of Services and Projects: From Awareness to Engagement. Publications, 6(2):27. doi:

https://doi.org/10.3390/publications6020027

Schöpfel, J. \& Fabre R. (2019) La question des revues dans la science ouverte : une approche fonctionnelle. I2D - Information, données \& documents, A.D.B.S., 2 (2). doi:10.3917/i2d.192.0109

Smart, P., Holmes, S., Lettice, F., Pitts, F.H., Zwiegelaar, J.B., Schwartz, G. \& Evans, S. (2019) Open Science and Open Innovation in a socio-political context: knowledge production for societal impact in an age of post-truth populism. R\&D Management, 49: 279297. doi: https://doi.org/10.1111/radm.12377

Stodden, V. (2010). Open science: policy implications for the evolving phenomenon of userled scientific innovation, Jcom 09(01). doi: https://doi.org/10.22323/2.09010205 Timmermann, M. (2019). A collective challenge: Open science from the perspective of science Europe. VOEB-Mitteilungen, 72 (2). doi: https://doi.org/10.31263/voebm.v72i2.2831 Vanholsbeeck, M. (2017) La notion de Science Ouverte dans l'Espace européen de la recherche. Revue française des sciences de l'information et de la communication, 11. doi:https://doi.org/10.4000/rfsic.3241

Vicente-Saez, R. \& Martinez-Fuentes, C. (2018) Open Science now: A systematic literature review for an integrated definition. Journal of Business Research 88, 428-436.

doi:10.1016/j.jbusres.2017.12.043

Vicente-Saez, R., Gustafsson R. \& Van den Brande L. (2020) The dawn of an open exploration era: Emergent principles and practices of open science and innovation of university research teams in a digital world. Technological Forecasting and Social Change 156. doi:https://doi.org/10.1016/j.techfore.2020.120037

Walsh, J.P. \& Huang, H. (2014) Local context, academic entrepreneurship and open science: Publication secrecy and commercial activity among Japanese and US scientists. Research Policy 43, 245-260. doi:10.1016/j.respol.2013.10.003 Wong, S., Ramos-Toledano, J., Rojas-Mora, J. (2018) Sobre la in-compatibilidad de la ciencia abierta con la novedad como estándar de patentabilidad. Revista Jurídicas 15 (2), 88-103. doi: 10.17151/jurid.2018.15.2.6. 
Xafis, V. \& Labude, M. (2019) Openness in Big Data and Data Repositories. ABR 11, 255273. doi:https://doi.org/10.1007/s41649-019-00097-z

\section{Appendixes}

Appendix A: Search strings and their results

\begin{tabular}{|c|c|c|c|}
\hline Database & Search keywords & Results & $\begin{array}{l}\text { Selected } \\
\text { papers_Policies }\end{array}$ \\
\hline \multirow[t]{4}{*}{ Scopus } & TITLE-ABS-KEY ( "ciencia abierta") & 16 & 2 \\
\hline & TITLE-ABS-KEY ( "ciência aberta" ) & 15 & 1 \\
\hline & TITLE-ABS-KEY ( "science ouverte" ) & 7 & 0 \\
\hline & $\begin{array}{l}\text { TITLE-ABS-KEY ( "open science" ) AND ( LIMIT- } \\
\text { TO ( DOCTYPE , "ar" ) ) AND ( LIMIT-TO ( } \\
\text { SUBJAREA, "MEDI" ) OR LIMIT-TO ( SUBJAREA } \\
\text {, "BIOC" ) OR LIMIT-TO ( SUBJAREA , "NEUR" ) } \\
\text { OR LIMIT-TO ( SUBJAREA , "AGRI" ) OR LIMIT- } \\
\text { TO ( SUBJAREA, "ENVI" ) OR LIMIT-TO ( } \\
\text { SUBJAREA, "PHYS" ) OR LIMIT-TO ( } \\
\text { SUBJAREA, "EART" ) OR LIMIT-TO ( } \\
\text { SUBJAREA, "PHAR" ) OR LIMIT-TO ( } \\
\text { SUBJAREA, "CHEM" ) OR LIMIT-TO ( } \\
\text { SUBJAREA, "HEAL" ) OR LIMIT-TO ( } \\
\text { SUBJAREA, "CENG" ) OR LIMIT-TO ( } \\
\text { SUBJAREA, "MATE" ) ) }\end{array}$ & 818 & 34 \\
\hline \multirow[t]{4}{*}{$\begin{array}{l}\text { Semantic } \\
\text { Scholar }\end{array}$} & "ciencia abierta" & 311 & 2 \\
\hline & "ciência aberta" & 281 & 0 \\
\hline & "science ouverte" & 211 & 4 \\
\hline & "open science" & 7820 & 3 \\
\hline \multirow[t]{3}{*}{$\begin{array}{l}\text { Google } \\
\text { Scholar }\end{array}$} & "ciencia abierta" & 13000 & 0 \\
\hline & "ciência aberta" & 3660 & 4 \\
\hline & "science ouverte" & 13700 & 0 \\
\hline
\end{tabular}




\begin{tabular}{|l|l|l|l|}
\hline "open science" & 383000 & 3 \\
\hline "politicas de ciencia abierta" & 58 & 3 \\
$\mid$ "Open Science Policies" & 567 & 6 \\
\hline "open science" policy & 147000 & 4 \\
\hline "políticas de ciência aberta" & 49 & 3 \\
\hline "politiques de science ouverte" & 7 & 1 \\
\hline
\end{tabular}

Appendix B: Compiled list of references and their characteristics

https://docs.google.com/spreadsheets/d/1gVf 2oylPlpojsHh4mc78p7GHTdkcphUqMtDihFvJ Cc/edit?usp=sharing 